\title{
Consequences of constitutive and induced variation in plant nutritional quality for immune defence of a herbivore against parasitism
}

\author{
Tibor Bukovinszky • Erik H. Poelman • Rieta Gols • \\ Georgios Prekatsakis · Louise E. M. Vet • \\ Jeffrey A. Harvey $\cdot$ Marcel Dicke
}

Received: 15 October 2008 / Accepted: 4 February 2009 / Published online: 7 March 2009

(c) The Author(s) 2009. This article is published with open access at Springerlink.com

\begin{abstract}
The mechanisms through which trophic interactions between species are indirectly mediated by distant members in a food web have received increasing attention in the field of ecology of multitrophic interactions. Scarcely studied aspects include the effects of varying plant chemistry on herbivore immune defences against parasitoids. We investigated the effects of constitutive and herbivoreinduced variation in the nutritional quality of wild and cultivated populations of cabbage (Brassica oleracea) on the ability of small cabbage white Pieris rapae (Lepidoptera, Pieridae) larvae to encapsulate eggs of the parasitoid Cotesia glomerata (Hymenoptera, Braconidae). Average encapsulation rates in caterpillars parasitised as first instars were low and did not differ among plant populations, with caterpillar weight positively correlating with the rates of encapsulation. When caterpillars were parasitised as second instar larvae, encapsulation of eggs increased. Caterpillars were larger on the cultivated Brussels sprouts plants and exhibited higher levels of encapsulation compared with caterpillars on plants of either of the wild cabbage populations. Observed differences in encapsulation rates between plant populations could not be explained exclusively by differences in host growth on the different Brassica popula-
\end{abstract}

Communicated by Thomas Hoffmeister.

T. Bukovinszky $(\bowtie) \cdot$ E. H. Poelman $\cdot$ R. Gols $\cdot$ G. Prekatsakis ·

L. E. M. Vet - M. Dicke

Laboratory of Entomology, Department of Plant Sciences,

Wageningen University, PO Box 8031,

6700 EH Wageningen, The Netherlands

e-mail: tibor.bukovinszky@wur.nl

L. E. M. Vet - J. A. Harvey

Department of Multitrophic Interactions, Netherlands Institute

of Ecology, PO Box 40, 6666 ZG Heteren, The Netherlands tions. Previous herbivore damage resulted in a reduction in the larval weight of subsequent herbivores with a concomitant reduction in encapsulation responses on both Brussels sprouts and wild cabbage plants. To our knowledge this is the first study demonstrating that constitutive and herbivore-induced changes in plant chemistry act in concert, affecting the immune response of herbivores to parasitism. We argue that plant-mediated immune responses of herbivores may be important in the evaluation of fitness costs and benefits of herbivore diet on the third trophic level.

Keywords Encapsulation - Host-parasitoid interaction . Plant nutritional quality $\cdot$ Multitrophic interactions

\section{Introduction}

An important challenge in contemporary ecology is to understand how trophic interactions between species can be mediated indirectly by other species, and how such interactions affect the dynamics and structure of multitrophic communities (Polis and Strong 1996; Vos et al. 2001; Werner and Peacor 2003). Considerable research has focussed on the role of herbivore-mediated trophic cascades of plant defence compounds. These cascades can affect natural enemies and thus influence the selection pressures that herbivores exert on plant defence (Hunter and Price 1992; Hunter 2003; Vet and Godfray 2007; Poelman et al. 2008). Plant nutritional traits have been shown to influence attack on herbivores by carnivores, and it has been argued that differences in concentrations of plant allelochemicals may have contributed to the observed differences found in endoparasitoid diversity in tropical and temperate zones (Gauld et al. 1992; Coley and Barone 1996; Dyer et al. 2007). Consequently, this may have driven differential adaptive 
responses in specialist herbivores: they might either actively sequester or detoxify plant allelochemicals. Sequestered toxins are often repellent to predators and/or are directly toxic to endoparasitoids (the 'nasty-host hypothesis' sensu Gauld et al. 1992; Dyer and Bowers 1996; Dyer and Coley 2002), whereas detoxification incurs physiological costs with possible consequences for hostparasitoid interactions (Muller et al. 2003; Kraaijeveld et al. 2001; Kapari et al. 2006).

Endoparasitoids have evolved an intimate relationship with their hosts and, as a consequence, herbivore physiological defences may respond to parasitoid attack in complex ways (Godfray 1994). When attacked by a parasitoid, a host may defend itself against parasitism by e.g. mounting a cellular response to encapsulate parasitoid eggs (Kraaijeveld et al. 2001). However, for the host, both the maintenance of such a defensive apparatus and the active process of mounting a defence after attack are costly (Kraaijeveld et al. 2001). Phenotypic traits (e.g. vigour) of hosts likely influence the degree to which immune reactions can be expressed. In turn, the host's ability to encapsulate parasitoid eggs is affected by several factors including host stage or age (Brodeur and Vet 1995; Ojala et al. 2005; Rantala and Roff 2005) as well as nutritional traits of the host's food (Turlings and Benrey 1997; Ferrari and Godfray 2006). Hence, physiological changes in the immune reaction can be a consequence of reduced host growth (i.e. vigour) on low quality plants, e.g. due to an inability to build up or allocate energetic reserves necessary for mounting an immune defence reaction (Vinson and Barbosa 1987; Kraaijeveld et al. 2001). In this context, if detoxification of secondary plant chemicals weakens the host's immune defences, either through body mass or indirectly, this may lead to higher susceptibility to endoparasitoid attack.

Plants show great inter- and intra-specific variation in constitutive and herbivore-induced defence traits (Gols et al. 2008a, b), with a knock-on effect on the performance and behaviour of higher trophic levels. Thus, defence traits of herbivores may be influenced indirectly when plants in the field are sequentially or simultaneously attacked by other herbivore species. This underlines the need for incorporating complexity in the community context when studying functional constraints in host-parasitoid interactions (Harvey 2005). Clearly, the effects of constitutive variation in immune responses of hosts to parasitoid attack should be evaluated in concert with those of herbivoreinduced variation in plant nutritional quality.

In this study we investigated the effects of constitutive and herbivore-induced variation in nutritional quality of wild and cultivated populations of cabbage (Brassica oleracea) on the ability of the small cabbage white Pieris rapae L. (Lepidoptera, Pieridae) to encapsulate eggs of the parasitoid Cotesia glomerata (Hymenoptera, Braconidae).
Cotesia glomerata is a gregarious braconid endoparasitoid that frequently attacks larvae of cabbage whites such as Pieris brassicae and P. rapae in the field. Field and laboratory studies have demonstrated that $P$. rapae shows an encapsulation response to $C$. glomerata eggs (Brodeur and Vet 1995; Geervliet et al. 2000). Caterpillar age influences encapsulation rates in this system, with stronger immune responses observed in second and third than in first instar larvae (Brodeur and Vet 1995). Secondary metabolites have been intensively studied within the Brassicaceae, with glucosinolates produced by these plants representing important defence compounds that have been shown to affect multitrophic interactions (Van Dam et al. 2004; Raybould and Moyes 2001; Harvey et al. 2003). Encapsulation rates of $C$. glomerata eggs by $P$. rapae may differ on distantly related brassicaceous plant species (Benrey and Denno 1997), but the effect of intraspecific variation in plant quality on host immune responses has received little empirical attention and has generally been based on studies with cultivated plant varieties (Karimzadeh and Wright 2008). Although the effects of herbivore-induced responses in wild and cultivated Brassicas on herbivore and parasitoid development have been studied, nothing is known about how these herbivore-induced changes affect host immune responses to parasitism.

Populations of wild B. oleracea grow along the English Channel and Atlantic coastlines of the United Kingdom and France. Foliar glucosinolate concentrations measured as constitutive and herbivore-induced traits, as well as herbivore and parasitoid development have been studied in several wild $B$. oleracea populations and in a domesticated cultivar (Harvey et al. 2007; Gols et al. 2008a, b). Based on this information, we have selected two wild populations (Old Harry and Kimmeridge) and a cultivar and studied their influence on herbivore immune responses. Furthermore, we investigated the effect of herbivore-induced variation in plant traits on the immune response by $P$. rapae to parasitism, by inducing plants with larval feeding by a congeneric species, the large cabbage white ( $P$. brassicae).

\section{Materials and methods}

\section{Plants}

A cultivated cabbage variety, Brussels sprouts (Brassicae oleracea gemmifera cv. Cyrus), and two wild populations of B. oleracea (Kimmeridge and Old Harry) were used in the experiments. Seeds of the two wild B. oleracea originated from natural populations growing in grassy chalk habitat on the English Channel coast of southern England (Dorset), approximately $10 \mathrm{~km}$ from each other (Gols et al. 2008b). The wild populations have been shown to differ 
significantly in constitutive and inducible levels of glucosinolates (Gols et al. 2008b). All plants were reared in a greenhouse compartment $\left(21 \pm 5^{\circ} \mathrm{C}, 50-70 \% \mathrm{RH}\right.$ and L16-D8 photoperiod) in pots (0.7 1) filled with potting soil (Lentse potgrond; Lent, The Netherlands). When light intensity dropped below $500 \mu \mathrm{mol}$ photons $\mathrm{m}^{-2} \mathrm{~s}^{-1}$, additional illumination was provided with mercury vapour lamps. Plants were fertilised on a weekly basis with $100 \mathrm{ml}$ nutrient solution [KristalonTM, concentration $3 \mathrm{~g} / 1$, (16N: 6P:20K:3Mg); FrontierAgriculture, Witham St. Hughs, UK]. Plants were all 7- to 8-weeks old, with 6-7 leaves, when used in the experiments.

\section{Insects}

Laboratory cultures of the insects were maintained at $22 \pm 2{ }^{\circ} \mathrm{C}, 60 \pm 10 \% \mathrm{RH}$ and L16-D8 photoperiod. The herbivores $P$. rapae and $P$. brassicae were reared on Brussels sprouts plants (Brassica oleracea gemmifera cv. Cyrus); C. glomerata was reared on caterpillars of P. brassicae. Cocoons were collected from the general parasitoid culture and maintained in cages without any hosts, hostrelated cues (i.e. silk, faeces, frass) or plant material being present. Emerging wasps were provided with water and honey ad libitum and were allowed to mate. Wasps were 5to 10-days old when used in experiments.

\section{Experimental set-up}

To study the effects of constitutive and herbivore-induced variation in plant nutritional quality on encapsulation rates, two experiments were conducted. In experiment I, we examined two aspects: (1) the consequences of constitutive variation in secondary plant chemistry, and (2) the effect of host age on the immune defence of the host against parasitism. In experiment II, we examined the consequences of both constitutive and induced variation in plant nutritional quality on immune defence of the host against parasitism. All experiments were carried out in a greenhouse compartment $\left(22 \pm 2^{\circ} \mathrm{C}, 65-75 \% \mathrm{RH}\right.$ and L16-D8 photoperiod). Eggs of $P$. rapae were obtained by placing three plants of each population in a cage with $P$. rapae butterflies for $24 \mathrm{~h}$. Neonate larvae were placed onto 16 experimental plants of each $B$. oleracea population using a small brush, at a density of eight larvae per plant, distributed in pairs on four leaves. In experiment I, larvae were allowed to feed on the plants either for $24 \mathrm{~h}$ (i.e. as first instars only) or $48 \mathrm{~h}$ (i.e. when they reached the second instar). These larvae were then collected and individually parasitised by $C$. glomerata. Parasitoids used for parasitising caterpillars were randomly selected from a cage containing individuals of the same age. An individual female parasitoid was offered a maximum of five hosts. Larvae were redistributed randomly within the treatment groups, but not necessarily on the same plant individual from which they had originated. Two days after parasitism, caterpillars were weighed individually on a Cahn microbalance C-33 (Cahn Instruments, Madison, WI) and subsequently dissected under a binocular microscope to check for encapsulated eggs. Encapsulated eggs are recognised as opaque whitish bodies floating in the haemocoel, usually as clusters of eggs, whereas non-encapsulated eggs are transparent and floating individually in the haemocoel (Brodeur and Vet 1995). We measured encapsulation both as the fraction of the host population showing an immune response (i.e. incidence), and the fraction of eggs laid in a single host that were in the process of being encapsulated (i.e. rate). Encapsulation was confirmed when at least one encapsulated egg was found in an individual.

In experiment II, we tested the effects of herbivoreinduced changes in plant nutritional quality on encapsulation rates by the host. To induce secondary plant chemistry, eight plants from each of the three $B$. oleracea lines were infested with eight first instar $P$. brassicae larvae, which were allowed to feed on the plants for 7 days. Eight uninfested Brussels sprouts and wild (Old Harry) plants served as control. There were not enough plants available to include uninfested Kimmeridge plants. After the 7-day induction period, the $P$. brassicae larvae were removed and replaced by neonate larvae of $P$. rapae (obtained as described in the first experiment). The $P$. rapae larvae were distributed on induced and uninduced plants at a density of 10-20 larvae per plant. We used a higher host density compared to the first experiment because we anticipated higher mortality of $P$. rapae larvae on induced plants. $P$. rapae caterpillars were parasitised in the late second instar (i.e. $72 \mathrm{~h}$ after hatching) and were redistributed randomly on experimental plants. Two days after parasitism, caterpillars were weighed individually and then dissected under a binocular microscope to record the encapsulation of eggs.

\section{Data analysis}

Incidence (binary data) and rates (fractions) of encapsulation were considered as response variables with binomial distributions for errors and were modelled as logits using generalized linear models. In experiment I, the effects of plant population on host immune responses were analysed separately for the two host-age cohorts. Plant population was included in the model as a fixed factor, and larval weight at dissection and clutch size (=number of eggs laid in host) as covariates.

In experiment II, plant type (i.e. B. oleracea population and induction) was included as a class variable, with larval weight at dissection and clutch size as covariates. As the experimental design was unbalanced (no uninduced plants of Kimmeridge were available), we first performed an 
overall test of homogeneity across all treatment groups. The Kimmeridge group was then removed from subsequent analysis to allow the analysis of a factorial design, where the effects of constitutive and herbivore-induced variation in plant nutrition quality and their interaction could be tested.

The comparison of main effects (type 3 analysis) and interactions was based on likelihood ratio statistics, and when a significant difference was found, pairwise comparisons were carried out by estimating linear contrasts between treatment groups. When overdispersal was detected in the analysis of encapsulation rates (fractions), we allowed the variance functions of the binomial distribution to have a multiplicative overdispersion factor by dividing the square root of the deviance of the model by the degrees of freedom (McCullagh and Nelder 1989).

Caterpillar growth in the treatments was analysed by a general linear model, followed by post-hoc tests (TukeyHSD) to separate treatment groups when main effects or their interactions were significant. In all the comparisons, the level of significance was $\alpha=0.05$. The statistical software package SAS 8.2 (http://www.sas.com/) was used in all analyses.

\section{Results}

Experiment I: Brassica population and host age

Larval weights of caterpillars parasitised in the first instar were significantly different among the plant populations $\left(F_{2,132}=5.14, P=0.007\right)$; caterpillars that had been feeding on Kimmeridge plants (mean \pm SE: $0.92 \pm 0.03 \mathrm{mg}$ ) were slightly heavier than caterpillars feeding on Brussels sprouts $(0.78 \pm 0.04 \mathrm{mg})$ and Old Harry $(0.78 \pm 0.03 \mathrm{mg})$ plants. Clutch size of $C$. glomerata in $P$. rapae varied considerably in all treatments (3-54 eggs per host). Average incidence and rates of encapsulation in caterpillars parasitised as first instars were low: $15.6 \%$ of the caterpillars encapsulated at least one parasitoid egg and the mean rate of encapsulation per host was $6.7 \%$. Incidences and rates of encapsulation in caterpillars parasitised in the first instar were not different among plant populations (incidence: $\chi_{2}^{2}=2.93, P=0.232$, Fig. 1a; rate: $\chi_{2}^{2}=4.63, P=0.099$, Fig. 1b). Caterpillar weight correlated positively with incidence $\left(\chi_{1}^{2}=6.83, P=0.009\right)$ and rate of encapsulating eggs $\left(\chi_{1}^{2}=4.31, P=0.038\right)$. Encapsulation was less likely with increasing clutch size, as was indicated by a negative effect of the total number of eggs on immune responses
Fig. 1 Encapsulation of Cotesia glomerata eggs when the host Pieris rapae was reared on different wild ( $\mathrm{K}$ and $\mathrm{OH})$ and cultivated (BS) populations of Brassica oleracea. Proportion of parasitised caterpillars with at least one encapsulated egg found (i.e. incidence), and average proportion of encapsulated eggs per caterpillar (i.e. rate) in $\mathbf{a}, \mathbf{b}$ first instar and c,d second instar larvae. Numbers indicate sample size. Different lower case letters indicate significant differences between treatment groups. Error bars SEM
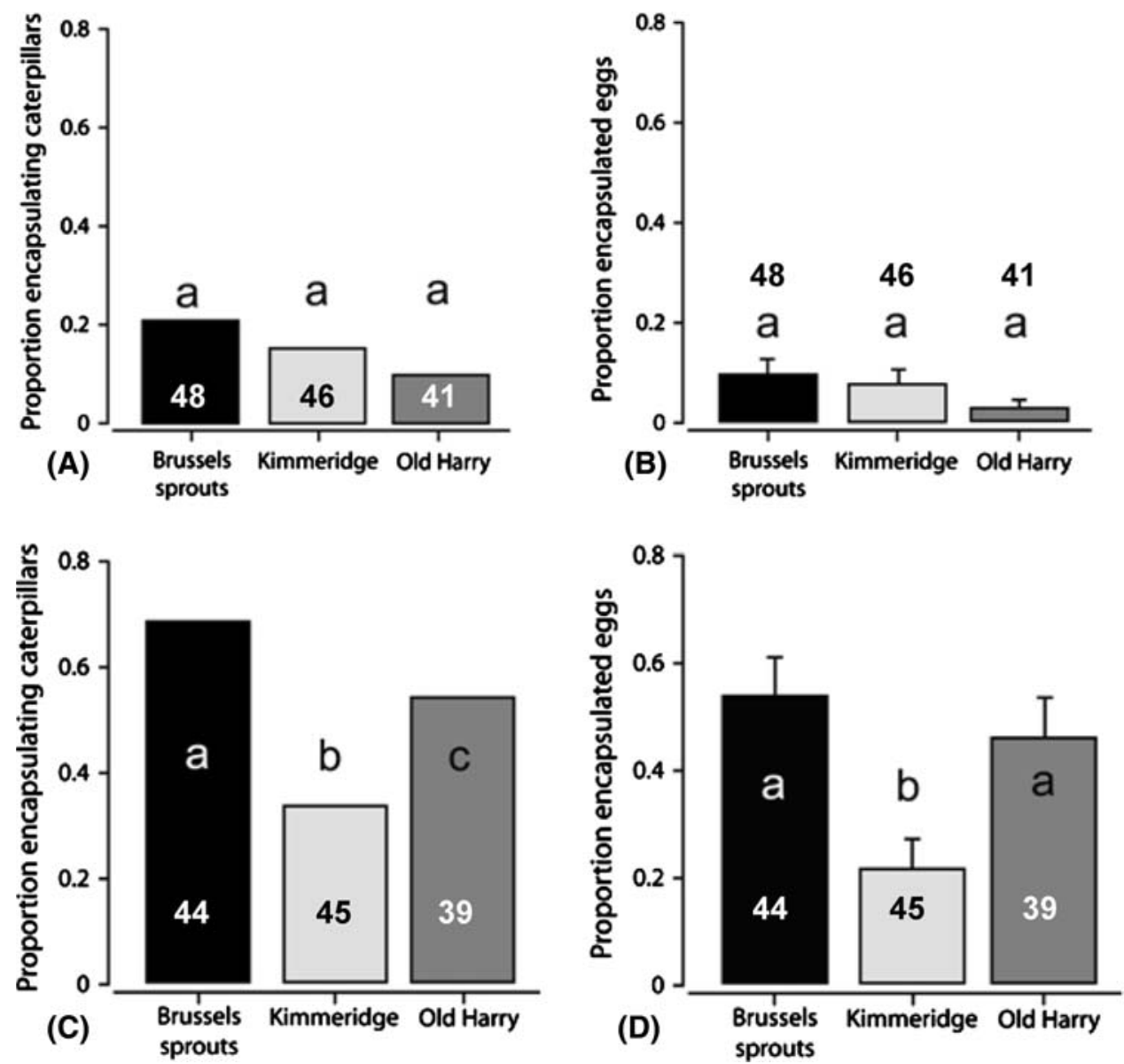


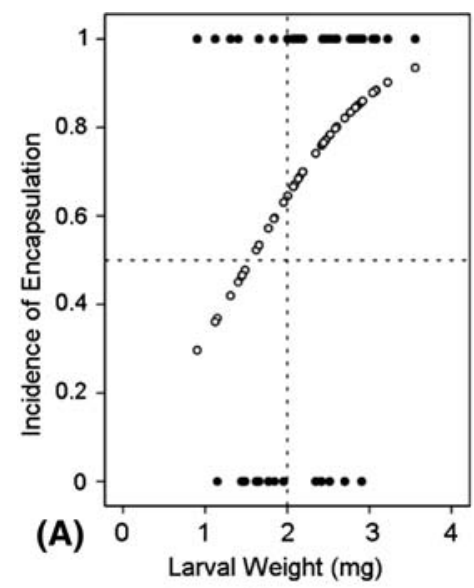

Brussels sprouts

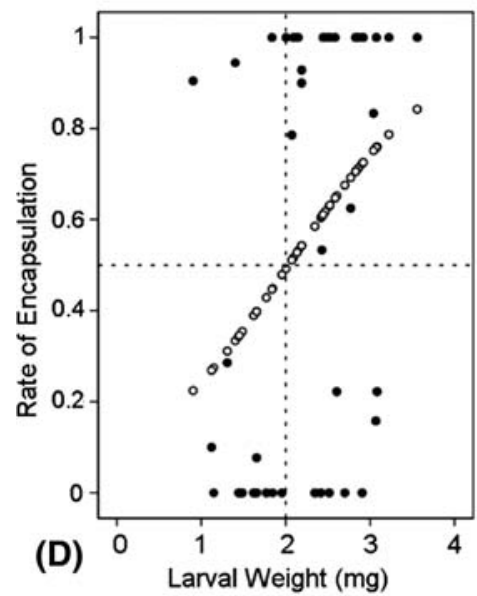

Brussels sprouts
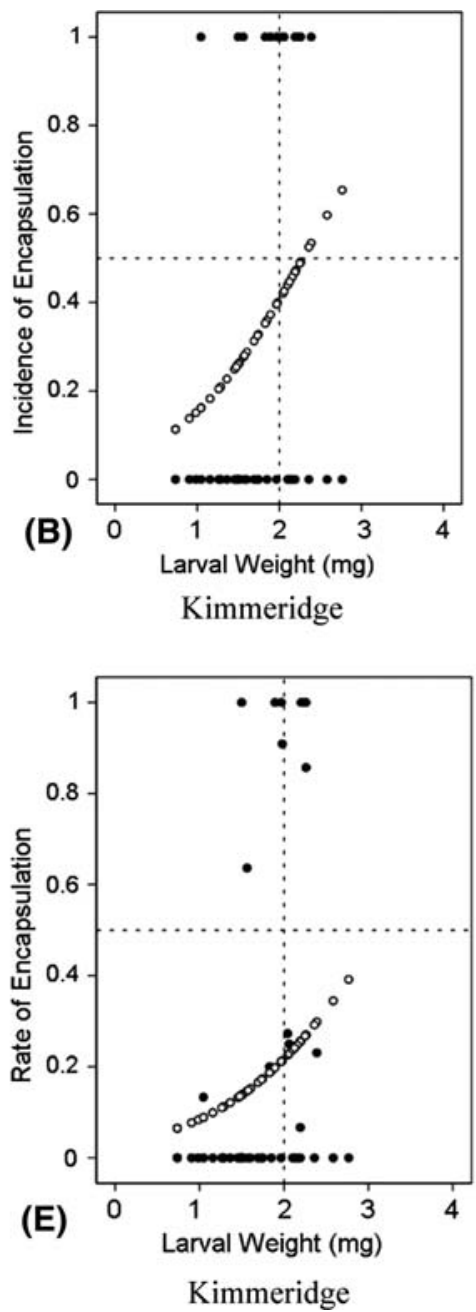
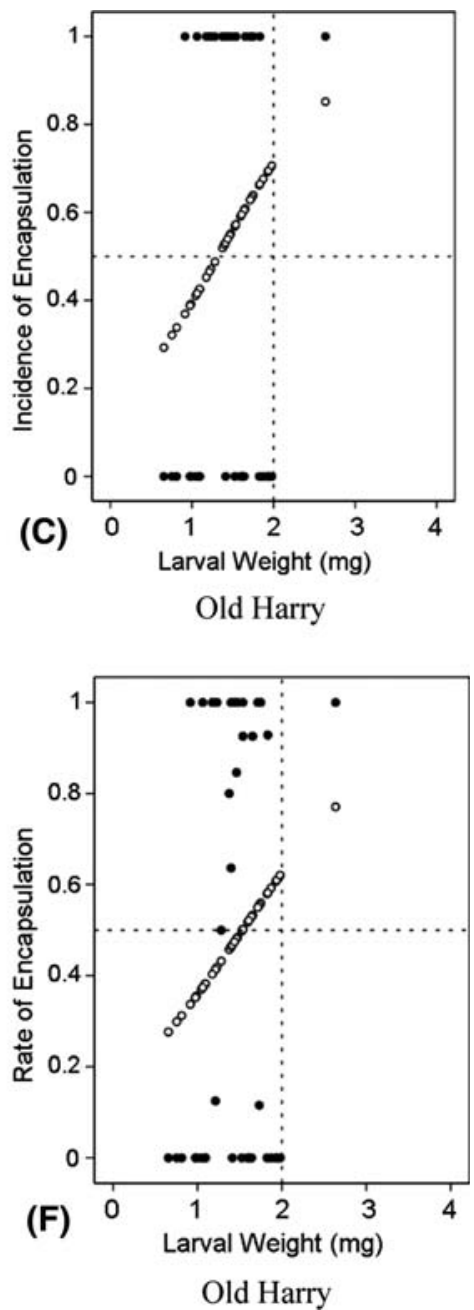

Fig. 2 The effect of larval weight on encapsulation of parasitoid eggs by $P$. rapae parasitised in its second instar, when reared on different populations of B. oleracea. Encapsulation levels were compared as a-c the proportion of parasitised caterpillars with at least one

(incidence: $\chi_{1}^{2}=6.99, \quad P=0.008, \quad$ rate: $\quad \chi_{1}^{2}=15.16$, $P<0.001)$.

Larval weights of caterpillars parasitised in the second instar were different among plant populations $\left(F_{2,125}=24.74\right.$, $P<0.001)$; caterpillars were heaviest on Brussels sprouts $(2.2 \pm 0.1 \mathrm{mg})$, significantly lighter on Kimmeridge $(1.7 \pm$ $0.07 \mathrm{mg}$ ) and lightest on Old Harry $(1.4 \pm 0.06 \mathrm{mg})$ plants. The host immune response to parasitism was higher when caterpillars were parasitised in the second than in the first instar: on average $51.6 \%$ of the second instar caterpillars encapsulated at least one parasitoid egg, at a rate of $39.8 \%$ of parasitoid eggs being encapsulated per host. Incidences and rates of encapsulation in second instar caterpillars were different among plant populations (incidence: $\chi_{2}^{2}=7.97$, $P=0.019$, Fig. 1c; rate: $\chi_{2}^{2}=13.14, P=0.001$, Fig. $\left.1 \mathrm{~d}\right)$. Caterpillar weight positively correlated with the incidence of encapsulation $\left(\chi_{1}^{2}=10.66, P=0.001\right.$, Fig. $\left.2 \mathrm{a}-\mathrm{c}\right)$ as well as the rates of encapsulated eggs per host $\left(\chi_{1}^{2}=9.57, P=0.002\right.$, encapsulated egg found (i.e. incidence), and $\mathbf{d}-\mathbf{f}$ the average proportion of encapsulated eggs per caterpillar (i.e. rate). Black circles Observed values, open circles values estimated by logistic regression for binomial distribution of errors

Fig. 2d-f). When weight was included in the statistical model, the effect of plant population remained significant, indicating that observed differences in encapsulation between plant populations could not be explained by differences in the growth of hosts alone. The interaction between plant population and caterpillar weight was not significant, indicating an overall positive effect of larval weight on encapsulation on the three Brassica populations. The total number of parasitoid eggs laid in second instar larvae did not influence encapsulation (incidence: $\chi_{1}^{2}=0.03, P=0.862$, rate: $\chi_{1}^{2}=0.18$, $P=0.672)$.

Experiment II: constitutive and herbivore-induced variation in plant quality

On average, $58.3 \%$ of the caterpillars encapsulated at least one parasitoid egg, at a rate of $42.9 \%$ of parasitoid eggs being encapsulated per host. Encapsulation response varied 
significantly across treatment groups $\left(\chi_{4,259}^{2}=57.37\right.$, $P<0.001$, Fig. 3). A factorial analysis involving only Brussels sprouts and 'Old Harry' plants revealed that herbivore immune responses were influenced by both constitutive and herbivore-induced variation in plant nutrition quality. Caterpillars on Brussels sprouts plants showed a stronger encapsulation response than on 'Old Harry' plants (incidence: $\chi_{1}^{2}=7.54, P=0.006$; rate: $\chi_{1}^{2}=7.73, P=0.005$ ). Plant induction by previous herbivory resulted in lower encapsulation in Pieris caterpillars (incidence: $\chi_{1}^{2}=9.13$, $P=0.003$; rate: $\chi_{1}^{2}=4.23, P=0.039$ ). This reduction in
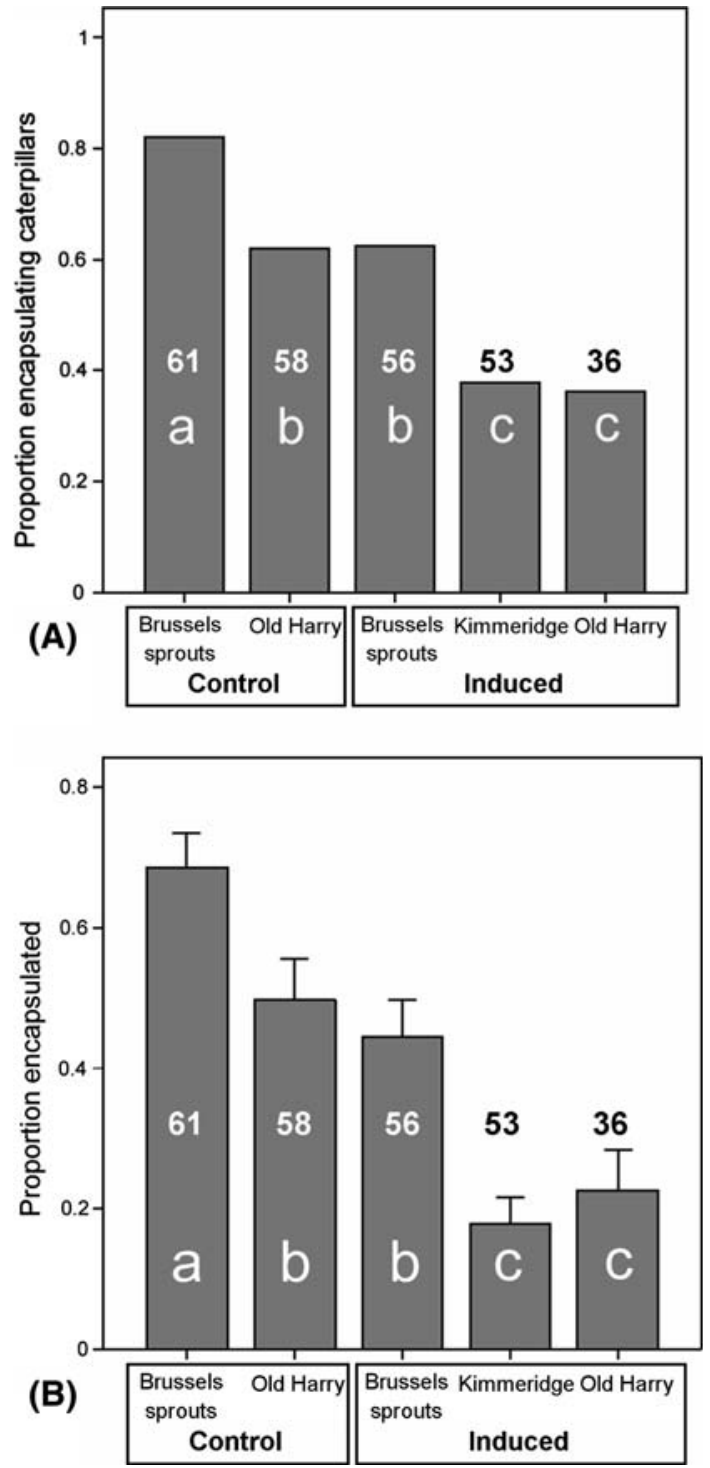

Fig. 3 Encapsulation of $C$. glomerata eggs by the host $P$. rapae, when reared on different populations of $B$. oleracea that were either damaged by Pieris brassicae feeding (induced) or not (control). Encapsulation levels were compared as a the proportion of parasitised caterpillars with at least one encapsulated egg found (i.e. incidence), and $\mathbf{b}$ the average proportion of encapsulated eggs per caterpillar (i.e. rate). Numbers show sample size. Different lower case letters indicate significant differences between treatment groups. Error bars SEM encapsulation due to plant induction did not differ on Brussels sprouts and Old Harry plants, as was indicated by nonsignificant interactions for incidence $\left(\chi_{1}^{2}=2.03, P=0.128\right)$ and rates $\left(\chi_{1}^{2}=1.04, P=0.309\right)$ of encapsulation.

Caterpillars were of similar weight on non-induced $(3.07 \pm 0.1 \mathrm{mg})$ and induced $(3.03 \pm 0.1 \mathrm{mg})$ Brussels sprouts plants and non-induced $(2.82 \pm 0.09 \mathrm{mg})$ 'Old Harry' plants, whereas herbivore-induction of 'Old Harry' plants resulted in reduced caterpillar weight $(2.2 \pm$ $0.13 \mathrm{mg}$ ). Weight alone had a significantly positive effect on encapsulation responses (incidence: $\chi_{1}^{2}=23.12, P<0.001$; rate: $\left.\chi_{1}^{2}=15.96, P<0.001\right)$. Caterpillars of low weight showed a stronger encapsulation response on Brussels sprouts than on Old Harry plants as was shown by a significant interaction for 'Brassica population' and 'host weight' (incidence: $\chi_{1}^{2}=5.94, P=0.015$; rate: $\chi_{1}^{2}=5.59, P=0.018$, Fig. 4). The interaction between weight and induction was significant for incidence $\left(\chi_{1}^{2}=6.81, P=0.009\right)$ of encapsulation responses and non-significant for rates of eggs encapsulated $\left(\chi_{1}^{2}=1.87, P=0.172\right)$. Larval weights $(1.79 \pm 0.11 \mathrm{mg})$ and encapsulation responses of caterpillars developing on herbivore-induced Kimmeridge plants were similar to those observed on induced 'Old Harry' plants (Figs. 3, 4).

\section{Discussion}

Plant defences and herbivore immune response

This study has reported that constitutive and herbivoreinduced variation in plant nutritional quality affects the immune response of herbivores to parasitism. The success of the encapsulation reaction by the host depends largely on larval vigour. Stress-induced changes in herbivore development through e.g. starvation or sequestration of toxic compounds can result in reduced immune defence against parasitism (Benrey and Denno 1997; Turlings and Benrey 1998; Hunter 2003). The results of our study showed that encapsulation responses in P. rapae, a herbivore that detoxifies plant allelochemicals, were driven partly by plantquality-mediated changes in host size and age. Consequently, encapsulation levels depended on host age and weight. As was found earlier by Brodeur and Vet (1995), host immune reactions were more pronounced when second instars were parasitised. Higher body weights in general correlated with higher encapsulation levels. Caterpillars were smaller, and exhibited weaker immune defences, on wild than on domestic Brassica plants, and previous damage to the plant reduced both caterpillar weights and encapsulation levels compared with uninduced plants.

However, differences in host weight alone cannot explain the effect of plant quality on encapsulation, suggesting that 

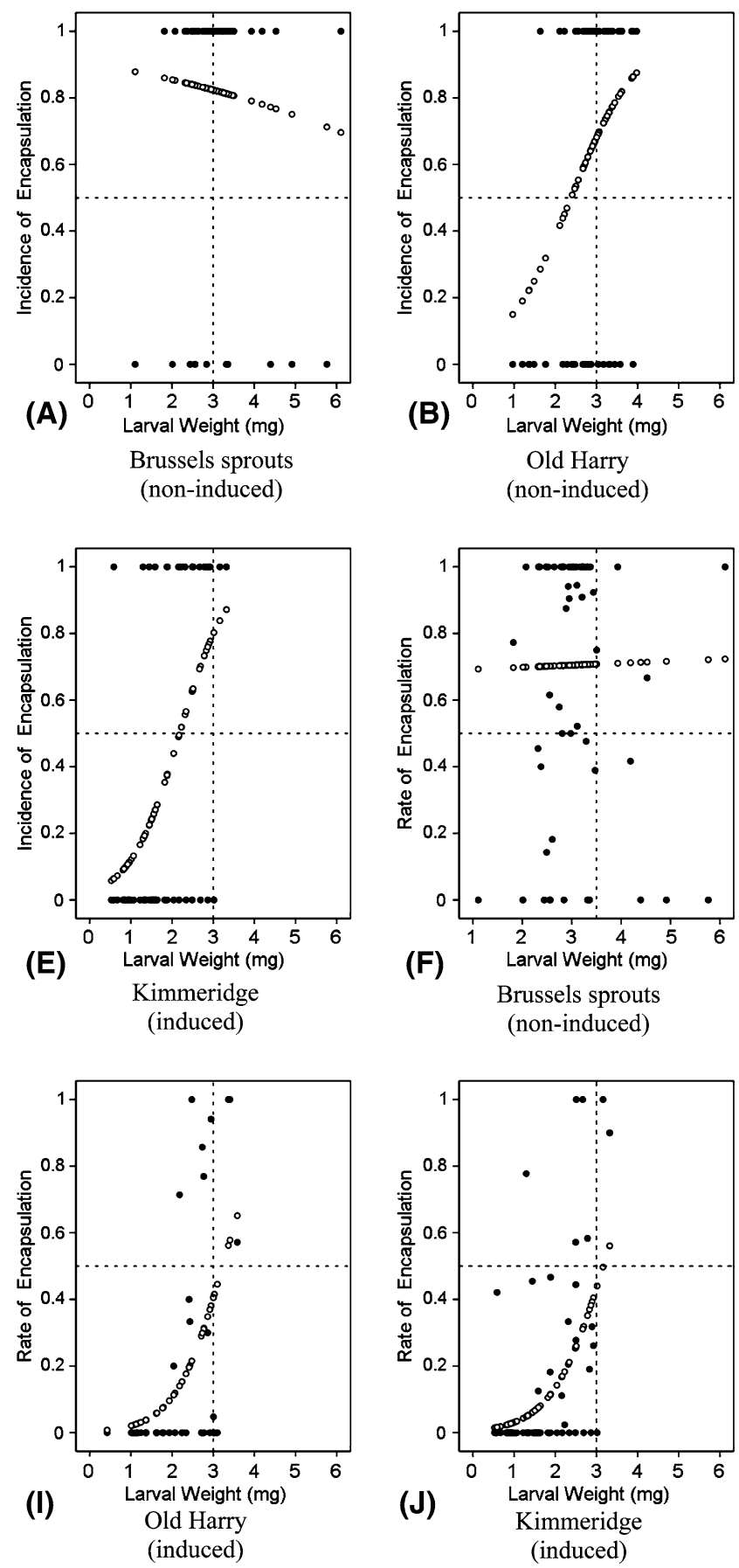

Fig. 4 The effect of larval weight on encapsulation of parasitoid eggs by $P$. rapae parasitised in its second instar, when reared on different populations of $B$. oleracea that were previously non-induced or induced by herbivory. Encapsulation levels were compared as a-e the proportion of parasitised caterpillars with at least one encapsulated

plant quality interacted with physiological aspects of encapsulation in more complex ways. Kapari et al. (2006) showed that delayed herbivore-induced changes in plant secondary chemistry may coincide with an increased ability to encapsulate parasitoid eggs. They suggested that this might be due to hosts investing in exploiting defensive plant compounds for
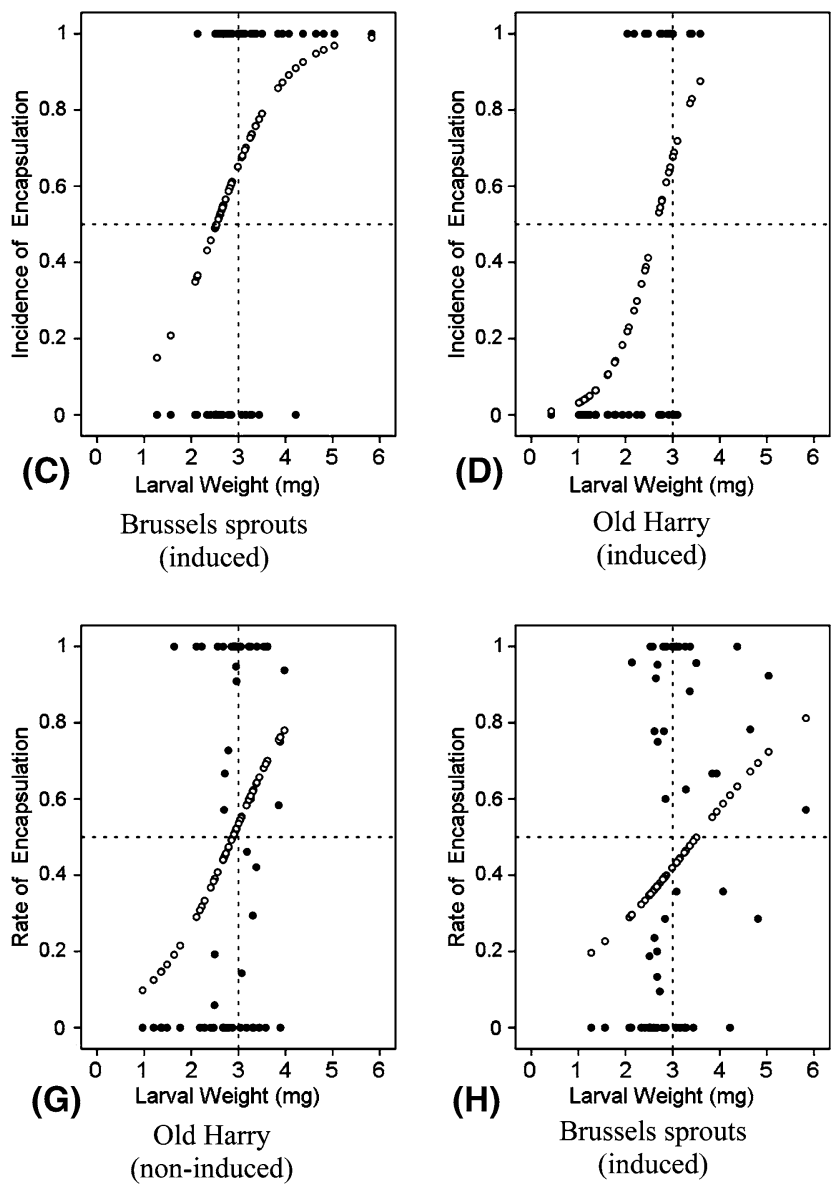

egg found (i.e. incidence), and $\mathbf{f}-\mathbf{j}$ the average proportion of encapsulated eggs per caterpillar (i.e. rate). Black circles Observed values, open circles values estimated by logistic regression for binomial distribution of errors

their own defence (Kapari et al. 2006). In contrast, we found that reduced host vigour was at least partially correlated with decreasing immune responses. Specialist herbivores like $P$. rapae are physiologically well-adapted to the secondary plant chemistry of Brassicas and are efficiently able to detoxify allelochemicals contained in plant tissues 
(Muller et al. 2003; Wittstock et al. 2004; Wheat et al. 2007), whereas other herbivore species feeding on Brassicas are known to sequester toxic plant secondary compounds (Muller and Brakefield 2003). Sequestering or detoxifying plant metabolites by herbivores is physiologically expensive and may, therefore, affect the ability of herbivores to maintain an immune defence apparatus or to build an encapsulation response (Bowers and Collinge 1992). Our results suggest that such a trade-off might exist in Pieris species (Freitak et al. 2003), an aspect deserving further study.

Endoparasitoids have evolved versatile ways to evade the host's immune defences. Particularly well studied are the roles played by venoms and virus like-particles (VLPs) or polydnaviruses (PDV) that reproduce in the calyxes of the parasitoid and are injected into the host during the oviposition sequence. Once they enter host cells and tissues, they are expressed, and are well-known to have an immune suppressive function (Strand and Pech 1995). More recently, a PDV gene has been shown to contribute to the suppression of host immunity in Cotesia genus parasitoids (Dupas et al. 2008). However, it is known that lepidopteran larvae also possess potent counter adaptations to parasitoid attack, such as the production of haemocytes and other factors that play an important role in the encapsulation process (Lavine and Strand 2002). As a result, immune responses of hosts may be either positive or negative, depending on the severity of a given factor, like induced changes in food plant quality (Klemola et al. 2007) or on trade-offs between different traits being influenced by plant quality in the herbivore or the parasitoid (Adamo 2004; Rantala and Roff 2005). To tease apart the underlying physiological interactions between plants and herbivores, and hosts and parasitoids, a mechanistic approach is needed where host plant effects on immune competence (phenoloxidase activity; haemocyte counts) and encapsulation levels are also measured (Adamo 2004; Kraaijeveld et al. 2001) with information on the cascading effects of plant chemistry on host vigour.

\section{Evolution of host-parasitoid interactions}

In all experiments, larval weight and encapsulation rates were highest on Brussels sprouts. Even when the plants had been exposed to previous herbivory, encapsulation responses on Brussels sprouts remained at levels comparable to those observed on uninduced wild cabbage populations. Recent studies carried out with the same Brassica populations showed that Old Harry plants contain higher constitutive levels of glucosinolates than Kimmeridge and Brussels sprouts plants (Gols et al. 2008a). Moreover, when damaged by herbivores, glucosinolate levels in the wild populations increase dramatically, whereas those in the cultivar stay at levels comparable to levels found in undamaged plants (Gols et al. 2008a). The observed differences in encapsulation on the Brassica populations points to a role for secondary chemistry as a potentially important selective force in shaping host-parasitoid interactions via modified immune responses of hosts to parasitism.

When the attacker is a gregarious parasitoid, and the encapsulation response is not complete, the consequences of immune responses for the herbivore are less clear, because a few parasitoids could still kill the host and complete their development. Benrey and Denno (1997) showed that, on certain plant species, an increased rate of encapsulation of parasitoid eggs by $P$. rapae correlated with lower parasitism by $C$. glomerata. This may suggest a positive effect of immune defence on herbivore survival in this system. Additional data analysis in our study suggested that plant-mediated changes in the immune response of the herbivore can have consequences for herbivore fitness in the $P$. rapae-C. glomerata system. When we considered only complete (i.e. 100\%) encapsulation responses on a subset of data (involving our factorial design), the effects of both Brassica population and herbivore-induction on immune responses of $P$. rapae remained significant. The encapsulation response in $P$. rapae seems to be a general response, which is even stronger against the congeneric solitary endoparasitoid $C$. rubecula, which is a specialist on $P$. rapae (Brodeur and Vet 1995). However, in the field, where variable multitrophic interactions are at work, a higher encapsulation response does not necessarily correlate with a lower parasitism and thus higher herbivore survival (Klemola et al. 2008). This warrants further studies to explore the consequences of plant-mediated immune responses on herbivore-parasitoid survival in communities where $P$. rapae is under attack by both parasitoid species.

Interestingly, light caterpillars showed higher encapsulation responses on Brussels sprouts plants than on plants from the wild cabbage populations. Since $P$. rapae has been maintained on the same Brussels sprouts cultivar for hundreds of generations, this suggests an adaptation to plant nutritional traits (e.g. primary- and secondary-chemistry) resulting in optimal utilisation of Brussels sprouts plants and strong immune responses. The observed differences could not be the result of adaptation in the host to parasitoid virulence due to rearing history, because in the cultures no gene flow is permitted between parasitoid-exposed and parasitoid-free $P$. rapae populations. Other studies showed similar differences in growth rates of unparasitised $P$. rapae, using the same laboratory strain as ours, supporting the idea of adaptation to local differences in plant chemistry (Gols et al. 2008a, b). However, to explicitly test the role of adaptation to plant chemistry in host-parasitoid immune interactions, encapsulation responses should be studied in natural plant-host-parasitoid populations, where the impact of plant chemistry and rearing history of higher 
trophic levels are then tested in reciprocal combinations. This is one of our future aims.

Our data have implications for the evolution of plantherbivore-parasitoid interactions. The effects of quantitative variation in plant allelochemistry on the strength of herbivore-natural enemy interactions, as well as the reciprocal role played by consumers in influencing defence responses in plants, has been the subject of considerable debate. Recent evidence suggests that variable factors may be at work, particularly in different bio-geographical realms. For example, Gauld et al. (1992) found that the diversity of endoparasitoids in the large family Ichneumonidae was actually lower in Costa Rican (tropical) biomes than in higher latitudes of comparable geographical size. It has been argued that plants are under much stronger frequency-dependent selection against herbivores in warm regions, and consequently tropical plants contain significantly higher levels of allelochemicals than plants in temperate zones (Coley and Barone 1996). In turn, this may have led to adaptive responses on the part of herbivores by increasing selection on dietary specialisation whereby many specialist herbivores actively sequester allelochemicals that function as a putative defence against their own natural enemies. This 'nasty host hypothesis' is in contrast with the immune stress hypothesis discussed here, whereby $P$. rapae and $P$. brassicae do not actively sequester allelochemicals (Muller et al. 2003) but must expend metabolic energy to excrete or detoxify plant toxins, which occur in lower levels in temperate than in tropical plants. A possible scenario is that the effects of a further increase in concentrations of allelochemicals in plant tissues may lead to a rapid switch over evolutionary time from benefits to the parasitoid (via stress to the herbivore's immune system) to the herbivore host (via directly toxic effects on parasitoid immatures), depending on constitutive and induced concentrations of allelochemicals.

To our knowledge this is the first study demonstrating that constitutive and herbivore-induced changes in plant chemistry act in concert affecting the immune response of herbivores to parasitism. A possible implication is that the consequences of plant defences for parasitoid fitness in the field will depend not only on reduced parasitoid growth and delayed development. The influence of plant chemistry on survival of parasitoid offspring as a function of changing host immune responses should also be quantified. This prediction further emphasises the view, recently advocated by many ecologists, that host-parasitoid interactions should be evaluated in a food web context where indirect (i.e. nonfeeding) relationships between community members (e.g. non-hosts vs hosts) are considered, which in turn may thus bring us closer to a better understanding of the factors influencing the assembly of host-parasitoid communities in natural and agro-ecosystems.
Acknowledgments We thank Leo Koopman, André Gidding and Frans van Aggelen for rearing of the insects. We thank James Bullock (Centre for Ecology and Hydrology, Wallingford, UK) for providing wild B. oleracea seeds. We are grateful for the constructive comments of two anonymous reviewers. This research was funded by a VICI Grant from The Netherlands Organization for Scientific Research, NWO (865.03.002) to T.B. and M.D., and the Strategic Fund of the Graduate School Experimental Plant Sciences (EPS) to E.H.P. The experiments comply with the current laws of the country in which they were performed.

Open Access This article is distributed under the terms of the Creative Commons Attribution Noncommercial License which permits any noncommercial use, distribution, and reproduction in any medium, provided the original author(s) and source are credited.

\section{References}

Adamo SA (2004) How should behavioural ecologists interpret measurements of immunity? Anim Behav 68:1443-1449

Benrey B, Denno RF (1997) The slow-growth-high-mortality hypothesis: a test using the cabbage butterfly. Ecology 78:987-999

Bowers MD, Collinge SK (1992) Fate of iridoid glycosides in different life stages of the buckeye, Junonia coenia (Lepidoptera, Nymphalidae). J Chem Ecol 18:817-831

Brodeur J, Vet LEM (1995) Relationships between parasitoid host range and host defence: a comparative study of egg encapsulation in two related parasitoid species. Physiol Entomol 20:7-12

Coley PD, Barone JA (1996) Herbivory and plant defences in tropical forests. Annu Rev Ecol Syst 27:305-335

Dupas S, Gitau CW, Branca A, Le Rü BP, Silvain JP (2008) Evolution of a polydnavirus gene in relation to parasitoid-host species immune resistance. J Hered 99:491-499

Dyer LA, Bowers MD (1996) The importance of sequestered iridoid glycosides as a defence against an ant predator. J Chem Ecol 22:1527-1539

Dyer LA, Coley PD (2002) Tritrophic interactions in tropical and temperate communities. In: Tscharntke T, Hawkins B (eds) Multitrophic level interactions. Cambridge University Press, pp 67-88

Dyer LA, Singer MS, Lill JT, Stireman JO, Gentry GL, Marquis RJ, Ricklefs RE, Greeney HF, Wagner DL, Morais HC, Diniz IR, Kursar TA, Coley PD (2007) Host specificity of Lepidoptera in tropical and temperate forests. Nature 448:696

Ferrari J, Godfray HCJ (2006) The maintenance of intraspecific biodiversity: the interplay of selection on resource use and on natural enemy resistance in the pea aphid. Ecol Res 1:9-16

Freitak D, Ots I, Vanatoa A, Horak P (2003) Immune response is energetically costly in white cabbage butterfly pupae. Proc R Soc B Biol Sci 270:S220-S222

Gauld ID, Gaston KJ, Janzen DH (1992) Plant allelochemicals, tritrophic interactions and the anomalous diversity of tropical parasitoids - the nasty host hypothesis. Oikos 65:353-357

Geervliet JBF, Verdel MSW, Snellen H, Schaub J, Dicke M, Vet LEM (2000) Coexistence and niche segregation by field populations of the parasitoids Cotesia glomerata and C. rubecula in the Netherlands: predicting field performance from laboratory data. Oecologia 124:55-63

Godfray HCJ (1994) Parasitoids behavioural and evolutionary ecology. Princeton University Press, Princeton, NJ

Gols R, Bukovinszky T, Van Dam NM, Dicke M, Bullock JM, Harvey JA (2008a) Performance of generalist and specialist herbivores and their endoparasitoids differs on cultivated and wild Brassica populations. J Chem Ecol 34:132-143

Gols R, Wagenaar R, Bukovinszky T, Van Dam NM, Dicke M, Bullock JM, Harvey JA (2008b) Genetic variation in the defence 
chemistry of wild cabbage populations and its effects on native herbivores and their endoparasitoids. Ecology 89:616-1626

Harvey JA (2005) Factors affecting the evolution of development strategies in parasitoid wasps: the importance of functional constraints and incorporating complexity. Entomol Exp Appl 117:1-13

Harvey JA, Van Dam NM, Gols R (2003) Interactions over four trophic levels: foodplant quality affects development of a hyperparasitoid as mediated through a herbivore and its primary parasitoid. J Anim Ecol 72:520-531

Harvey JA, Gols R, Wagenaar R, Bezemer TM (2007) Development of an insect herbivore and its pupal parasitoid reflect differences in direct plant defense. J Chem Ecol 33:1556-1569

Hunter MD (2003) Effects of plant quality on the population ecology of parasitoids. Agric For Entomol 5:1-8

Hunter MD, Price PW (1992) Playing chutes and ladders: heterogeneity and the relative roles of bottom-up and top-down forces in communities. Ecology 73:724-732

Kapari L, Haukioja E, Rantala MJ, Ruuhola T (2006) Defoliating insect immune defence interacts with induced plant defence during a population outbreak. Ecology 87:291-296

Karimzadeh J, Wright DJ (2008) Bottom-up cascading effects in a tritrophic system: interactions between plant quality and hostparasitoid immune responses. Ecol Entomol 33:45-52

Klemola N, Klemola T, Rantala M, Ruuhola T (2007) Natural hostplant quality affects immune defence of an insect herbivore. Entomol Exp Appl 123:167-176

Klemola N, Kapari L, Klemola T (2008) Host plant quality and defence against parasitoids: no relationship between levels of parasitism and a geometrid defoliator immunoassay. Oikos 117:926-934

Kraaijeveld AR, Limentani EC, Godfray HCJ (2001) Basis of the trade-off between parasitoid resistance and larval competitive ability in Drosophila melanogaster. Proc R Soc B Biol Sci 268:259-261

Lavine MD, Strand MR (2002) Insect hemocytes and their role in immunity. Insect Biochem Mole Biol 32:1295-1309

McCullagh P, Nelder JA (1989) Generalized linear models. Chapman and Hall, London

Muller C, Brakefield PM (2003) Analysis of a chemical defence in sawfly larvae: easy bleeding targets predatory wasps in late summer. J Chem Ecol 29:2683-2694

Muller C, Agerbirk N, Olsen CE (2003) Lack of sequestration of host plant glucosinolates in Pieris rapae and P. brassicae. Chemoecology 13:47-54
Ojala K, Julkunen-Tiitto R, Lindström L, Mappes J (2005) Diet affects the immune defence and life-history traits of an Arctiid moth Parasemia plantaginis. Evol Ecol Res 7:1153-1170

Poelman EH, Van Loon JJA, Dicke M (2008) Consequences of variation in plant defence for biodiversity at higher trophic levels. Trends Plant Sci 13:534-541

Polis GA, Strong DR (1996) Food web complexity and community dynamics. Am Nat 147:813-846

Rantala MJ, Roff DA (2005) An analysis of trade-offs in immune function, body size and development time in the Mediterranean Field Cricket, Gryllus bimaculatus. Funct Ecol 19:323-330

Raybould AF, Moyes CL (2001) The ecological genetics of aliphatic glucosinolates. Heredity 87:383-391

Strand MR, Pech LL (1995) Immunological compatibility in parasitoid-host relationships. Annu Rev Entomol 40:31-56

Turlings TCJ, Benrey B (1998) Effects of plant metabolites on the behavior and development of parasitic wasps. Ecoscience 5:321333

Van Dam NM, Witjes L, Svatos A (2004) Interactions between aboveground and belowground induction of glucosinolates in two wild Brassica species. New Phytol 3:801-810

Vet LEM, Godfray HCJ (2007) Multitrophic interactions and parasitoid behavioural ecology. In: Wajnberg $\mathrm{E}$, Bernstein $\mathrm{C}$, van Alphen J (eds) Behavioral ecology of insect parasitoids from theoretical approaches to field applications. Blackwell, Oxford, pp 231-252

Vinson SB, Barbosa P (1987) Interrelationships of nutritional ecology of parasitoids. In: Slansky F, Rodriguez JG (eds) Nutritional ecology of insects, mites and spiders and related invertebrates I. Wiley, New York, pp 673-695

Vos M, Berrocal SM, Karamaouna F, Hemerik L, Vet LEM (2001) Plant-mediated indirect effects and the persistence of parasitoidherbivore communities. Ecol Lett 4:38-45

Werner EE, Peacor SD (2003) A review of trait-mediated indirect interactions in ecological communities. Ecology 84:1083-1100

Wheat CW, Vogel H, Wittstock U, Braby MF, Underwood D, Mitchell-Olds T (2007) The genetic basis of a plant-insect coevolutionary key innovation. Proc Natl Acad Sci USA 104:20427-20431

Wittstock U, Agerbirk N, Stauber EJ, Olsen CE, Hippler M, MitchellOlds T, Gershenson J, Vogel H (2004) Successful herbivore attack due to metabolic diversion of a plant chemical defence. Proc Natl Acad Sci USA 101:4859-4864 